\title{
Is it time for a new attitude to "simultaneous" bilateral cataract surgery?
}

\author{
Guy T Smith, Christopher S C Liu
}

Almost every discussion on simultaneous bilateral cataract surgery (SBCS) for senescent cataracts begins with a comment on its controversial nature. ${ }^{1-3}$ The question is can the benefits of bilateral surgery justify the risk of simultaneous bilateral complications, in particular endophthalmitis? Operating on the second eye immediately after the first is an option that does have potential advantages. These can be separated into the clinical benefits to the patient and economic benefits to the patient, hospital, and society. It is the benefits and risks to the patient that are our primary duty as clinicians, and they will be the focus of this discussion. In this perspective we present an approach to "simultaneous" bilateral cataract extraction, and examine the risk of unilateral or bilateral complications following cataract extraction in light of the perceived benefits as they apply at the beginning of the 21 st century. The aim of the perspective is to remove the stigma from "simultaneous" bilateral cataract surgery, so that suitable patients may be offered this method of delivery of treatment.

\section{Our approach to simultaneous bilateral cataract surgery}

We begin by assuming that all patients are suitable for simultaneous bilateral cataract surgery (SBCS), unless they have a specific contraindication that increases the risk of complications (Table 1). These are broadly divided into conditions that increase the risk of endophthalmitis,

Table 1 Exclusion criteria for immediately sequential cataract surgery (ISCS)

\begin{tabular}{|c|c|}
\hline \multicolumn{2}{|l|}{ Exclusion criteria } \\
\hline Increased risk of infection & $\begin{array}{l}\text { - active adnexal and ocular surface infection } \\
\text { (including untreated blepharitis, mucocele) } \\
\text { - diabetes mellitus } \\
\text { - immunosuppression and immunodeficiency } \\
\text { (including systemic steroids) } \\
\text { - leukaemia/lymphoma } \\
\text { - iodine allergy }\end{array}$ \\
\hline $\begin{array}{l}\text { Increased risk of corneal } \\
\text { decompensation }\end{array}$ & $\begin{array}{l}\text { - endothelial dystrophy } \\
\text { - guttata }\end{array}$ \\
\hline $\begin{array}{l}\text { Increased risk of } \\
\text { inaccurate biometry }\end{array}$ & $\begin{array}{l}\text { - high myopia or } \mathrm{AL}>26 \mathrm{~mm} \\
\text { - high hyperopia or } \mathrm{AL}<21 \mathrm{~mm} \\
\text { AL difference between the eyes }>1 \mathrm{~mm} \\
\text { (unless supported by corresponding } \\
\text { anisometropia) } \\
\text { - previous refractive surgery }\end{array}$ \\
\hline Lenticular abnormalities & $\begin{array}{l}\text { - history of ocular trauma } \\
\text { - lens subluxation } \\
\text { - phacodonesis } \\
\text { - pseudoexfoliation }\end{array}$ \\
\hline Increased risk of high IOP & $\begin{array}{l}\text { - glaucoma } \\
\text { trabeculectomy } \\
\text { - previous iritis }\end{array}$ \\
\hline Uniocular cataract & \\
\hline
\end{tabular}

lenticular abnormalities, extremes of axial length, and keratometry that may make the biometry unreliable and conditions that may predispose to postoperative corneal oedema or decompensation, raised intraocular pressure, ocular inflammation, and retinal detachment. An informal survey of patients seen at our cataract clinic would suggest that up to one third of patients would be excluded by these criteria. Currently we do not carry out extensive preoperative systemic investigations on our patients and, therefore, there does remain an element of risk that there may be an undiagnosed condition such as leukaemia.

When visually significant bilateral senescent cataracts are diagnosed in the absence of exclusion criteria, the perceived risks and benefits of SBCS are discussed with the patients (Table 2). The patients' names are put on the waiting list for SBCS or unilateral cataract surgery, as they prefer. At preassessment, patients undergo a further full ocular examination and biometry. The perceived risks and benefits of SBCS are discussed again before seeking consent. If an exclusion criterion is present unilateral rather than SBCS is offered.

On the day of surgery the eyes are briefly examined again preoperatively to ensure that no contraindications to SBCS

Table 2 Benefits and risks of immediately sequential cataract surgery (ISCS)

\begin{tabular}{|c|c|}
\hline \multicolumn{2}{|l|}{ Benefits } \\
\hline To the patient & $\begin{array}{l}\text { One general anaesthetic, where required, for } \\
\text { surgery } \\
\text { - Improved visual function } \\
\text { One step visual rehabilitation } \\
\text { - No anisometropia between operations } \\
\text { - Fne pair of new glasses } \\
\text { Fewer hospital visits }\end{array}$ \\
\hline To the hospital & $\begin{array}{l}\text { - Only one preassessment visit } \\
\text { Only one admission for surgery } \\
\text { - More efficient use of theatre time } \\
\text { - More efficient use of clinic }\end{array}$ \\
\hline To society & $\begin{array}{l}\text { - Shorter waiting lists for surgery and clinics } \\
\text { Accompanying friends and relatives take less } \\
\text { time off work } \\
\text { - Less demand on hospital transport services }\end{array}$ \\
\hline \multicolumn{2}{|l|}{ Risks } \\
\hline $\begin{array}{l}\text { First eye intraoperative } \\
\text { complications result in } \\
\text { unilateral surgery }\end{array}$ & $\begin{array}{l}\text { - Vitreous exposure } \\
\text { - Suprachoroidal haemorrhage }{ }^{\star}\end{array}$ \\
\hline $\begin{array}{l}\text { Bilateral early postoperative } \\
\text { complications }\end{array}$ & $\begin{array}{l}\text { - Endophthalmitis }{ }^{\star} \\
\text { - Hyphaema } \\
\text { - Raised IOP } \\
\text { - Iris prolapse }\end{array}$ \\
\hline $\begin{array}{l}\text { Bilateral late postoperative } \\
\text { complications }\end{array}$ & $\begin{array}{l}\text { - Cystoid macular oedema } \\
\text { - Refractive surprise } \\
\text { - Epithelial ingrowth } \\
\text { - Corneal decompensation } \\
\text { - Fungal endophthalmitis }\end{array}$ \\
\hline
\end{tabular}

${ }^{\star}$ Catastrophic complications. 
have developed. The first eye to be operated on is marked as such and the pupils are dilated with phenylephrine $2.5 \%$ eye drops and cyclopentolate $1 \%$ eye drops four times an hour before surgery. Topical antibiotics are not used preoperatively. Diclofenac $0.1 \%$ eye drops four times an hour before surgery are instilled to stabilise the bloodaqueous barrier and inhibit intraoperative miosis.

The surgical team is well established and familiar with the operative technique. The surgery is usually carried out under general anaesthesia but may very occasionally be done under sub-Tenon's or topical anaesthesia. We prefer not to use peribulbar anaesthesia to avoid the small risk of bilateral ocular perforation, and poor vision in both eyes in the immediate postoperative period. The masked surgeon instils aqueous povidone iodine $5 \%$ into the conjunctival fornices of both eyes, followed by cleaning of the lids, cheek, nose, and brows working concentrically away from the eyes. The skin is dried before the drape is placed with the eye held open and lashes fully everted. A horizontal cut in the plastic material divides the plastic to be folded under the upper and lower lids, so the speculum traps the lashes and excludes the meibomium gland orifices from the surgical field. The drape is also pressed against the skin on the side of the nose to exclude communication with the anterior nares. The face is turned slightly to prevent pooling of irrigating fluid on the ocular surface.

Usually, a superiorly sited astigmatically neutral scleral tunnel is fashioned. A "divide and conquer" technique is usually used for phacoemulsification and the implant is usually a $5.5 \mathrm{~mm}$ diameter optic one piece poly(methylmethacrylate) (PMMA) lens. The viscoelastic is removed, the wound checked for integrity and sutured if necessary with $10 / 0$ Vicryl. The conjunctival flap is replaced over the scleral wound, subconjunctival cefuroxime is injected, and the eye is padded. If there are any complications such as posterior capsular breach, zonular dehiscence, excessive operating time, or phacoemulsification energy, surgery to the second eye is postponed. For this reason the term "simultaneous" bilateral cataract surgery is a misnomer for this type of surgery. Neither the surgeon nor the patient is irrevocably committed to having the second eye operated on unless everything has gone perfectly with the first eye. For this reason we prefer the term immediately sequential cataract surgery (ISCS).

Before the second eye is operated on, the surgeon and assistant rescrub. Alternatively, another surgeon and assistant scrub as the first eye operation comes to an end. The second eye is cleaned again with povidone iodine $5 \%$. The same surgical technique is used for the second eye. When both eyes have been operated on, a clear Cartella shield is applied to each eye, and the patients are taken back to the ward following recovery. Later an ophthalmologist from the operating team examines the patient for any complications before discharge. If surgery to the second eye has been cancelled, it is explained to the patient that the second eye will be operated on at a later date when the first eye is fully recovered. Patients are discharged on a regimen of steroid eye drops four times daily and antibiotic eye drops four times daily until reviewed in the follow up clinic. They are informed that if they experience problems with either eye-for example, increased redness, pain, or decreased vision, they should telephone or reattend immediately. This protocol has been successful with our unilateral phacoemulsifications.

Steps are taken to avoid epidemic endophthalmitis, the instruments are taken from a "phaco pack" held back from the previous week's batch, the sterility of that batch having been "proved" by the previous week's surgery. Intraocular substances such as adrenaline, antibiotics, or anaesthetic agents are not routinely used. Viscoelastic materials and balanced salt solutions made by different manufacturers, or from different batches if from the same manufacturer, are used for each of the two eyes.

\section{Why take the risk of performing immediately sequential bilateral phacoemulsification?}

The results from our unilateral surgery are stable and successful. Operating on the second eye immediately after the first is an option that has potential advantages.

\section{ADVANTAGES TO THE PATIENT}

Improved visual function

The expectations of patients are increasing all the time. It is no longer enough to remove the lens opacity, we must also try to optimise the patients' visual function. Visual perception is a highly complex multidimensional function, involving vernier acuity, colour perception, contrast sensitivity, and a host of other factors. The Snellen acuity is a measure of the patient's ability to resolve high contrast optotypes in minutes of arc, it only provides limited information about the patient's visual function, and none on the day to day effects of cataracts. Despite being firmly established, it should not be the sole criterion by which visual impairment caused by cataract and outcome of surgery are measured. Rather, "cataract surgery is indicated when a cataract causes functional disability considered by the patient to be sufficiently problematic to warrant undertaking the risks of cataract surgery, regardless of the VA of that patient." A "gold standard" for functional impairment related to vision does not exist. Several subjective measures of patients' visual function have been established..$^{5-12}$ The VF 14 shows moderate correlation with the visual acuity (VA) in the better eye, and the relation between the preoperative measured visual acuity and the Activities of Daily Vision Score (ADVS) is also stronger for the better eye. ${ }^{11}$ This suggests that the ability to perform many vision dependent activities is determined more by the acuity of the better eye than the acuity of the worse eye or the binocular vision. ${ }^{9}$ Despite this, a number of studies have shown that operating on the second eye gives a significant improvement in visual function and quality of life. ${ }^{8}{ }^{13}$ In 1993 Javitt and colleagues addressed the relative impact of surgery for the first, second, or both eyes simultaneously. ${ }^{7}$ Following extracapsular cataract surgery $(n=365)$ the amount of improvement in subjective visual function was approximately equal after surgery in the first and second eyes. However, patients undergoing SBCS were more likely to report an improvement in visual function (92\%) than patients undergoing cataract extraction in either the first $(76 \%)$ or second eye $(75 \%)(p=0.03)$ and were less likely to show no improvement than were patients undergoing cataract surgery in one eye. Multiregression analysis assessing all patients with cataract at baseline, and controlling for age, sex, and concurrent eye disease, demonstrated a significant increase in visual function following SBCS, compared with surgery in one eye $(p=0.05)$. $^{7}$

Where there is significant preoperative refractive error, surgery for the second eye is often expedited to avoid the effects of postoperative anisometropia. ISCS represents one end of the spectrum of possible intervals between operations. Many of the patients requiring cataract surgery are elderly, most of the studies on cataract surgery quote an average age in the $70 \mathrm{~s} .{ }^{14}$ Patients in this age group may have significant ocular and systemic comorbidity which may rob them of the potential benefits of ISCS if they have to wait 9-18 months for their second eye surgery. ${ }^{8} 1315$

Fewer visits to the hospital

Many patients have limited mobility in the preoperative and perioperative period which makes getting to hospital difficult. This often means that a relative or friend has to 
bring them, wait with them, and then take them home. By performing ISCS, complete visual rehabilitation is carried out in one step. There is only one preoperative assessment, one visit to theatre, one postoperative visit, one period of waiting for the eyes and refraction to stabilise, one visit to the optometrist, and no waiting for the second eye.

\section{ADVANTAGES TO HOSPITAL STAFF}

Each patient has to be assessed once only, booked in once by the nursing staff, and taken to theatre once by the porters. When general anaesthesia is required, removing both cataracts under one anaesthetic is advantageous to the patient and anaesthetist. In theatre after the first eye has been operated on, the only delay before beginning the next operation is the time required to rescrub and set up the new instruments (abolished where the second eye is operated on by a second surgeon assisted by another scrub nurse). There is no delay for taking out the patient and bringing the next one in, no need to readjust the foot pedals, microscope, or operating chair (except for surgeons who operate from the side or if a second surgeon is operating). The second eye tends to handle much like the first, which makes surgery like a continuation of the first eye. We have found that on average ISCS only adds 12 minutes to the usual case time of 28 minutes (from entering the operating theatre to leaving it). This means that there is proportionally more time spent on actual operating per session. For our theatre this allows surgery on eight eyes per list rather than five. Similarly in the clinics both eyes are examined whether the patient has had unilateral or bilateral surgery. The time taken for the actual examination is only a small fraction of the total consultation time, most of which is getting the patients positioned, explaining the diagnosis and management to the patients, and helping them out of the room. Again in effect this allows more "eyes" to be seen per clinic.

\section{ADVANTAGES TO SOCIETY}

Second eye surgery represents $35 \%$ of cataract extractions. ${ }^{14}{ }^{16}$ By performing ISCS more eyes can be operated on per list and the second eye is not added to the waiting list. In the short term this may produce a small increase in the number of patients on the waiting list, but in the long term ISCS would be expected to shorten the waiting list because the second eye has already been done. Treatment of both eyes makes more efficient use of clinic time, which is always oversubscribed. The reduced number of visits not only saves the patients' time, but also their friends' and relatives' time, who may have to take time off work to accompany them. It is also a more efficient use of the hospital transport facilities.

\section{The risks of modern cataract surgery}

In December 1997 the cataract surgical problem in the Fournal of Cataract and Refractive Surgery was "Under what conditions do you perform/consider bilateral simultaneous cataract extraction with intraocular lens (IOL) implantation. What special precautions do you take/advise when considering bilateral surgery?" 17 The replies could be grouped into "never," "no-wait eight weeks to avoid bilateral cystoid macular oedema," "no-wait one to two weeks to evaluate the refractive outcome," "yes-to avoid two general anaesthetics," and "yes-based on inclusion criteria." All the surgeons who offer simultaneous cataract surgery emphasised treating it as two separate operations, and all said they would discuss the risk of bilateral complications. But the problem is that the risk of bilateral complications is not known. We have assessed the complications and outcome of unilateral ECCE, phacoemulsification, and bilateral cataract extraction to compare the outcomes and risks, using published data following a Medline search. The complications can be categorised as intraoperative, early postoperative, and late postoperative, and subdivided into catastrophic and non-catastrophic. A catastrophic complication is one in which there is a reasonable likelihood of permanent visual loss in the affected eye.

INTRAOPERATIVE COMPLICATIONS

These are minimised with ISCS by not proceeding to the second eye if there are intraoperative complications with the first eye.

\section{NON-CATASTROPHIC COMPLICATIONS}

Vitreous exposure is the most important intraoperative complication, it is associated with a 5.3-fold (1.8 times to 16 times, $p=0.002)$ risk of endophthalmitis ${ }^{18}$ and also increases the risk of postoperative cystoid macular oedema. In a modern series of 319 cases of immediately sequential extracapsular cataract extraction (ECCE) Beatty and colleagues reported posterior capsule rupture in five eyes $(0.8 \%)$ and vitreous loss in two eyes $(0.3 \%)$. No patient had both eyes affected. Although there was one case of endophthalmitis $(0.16 \%)$ it was not stated if the posterior capsule had been breached. ${ }^{1}$ Ramsay and colleagues reported a posterior capsule rupture rate of $5 \%$ with vitreous loss in 3\%, there was one case of bilateral vitreous loss during 453 cases of immediately sequential ECCE. ${ }^{3}$ Diaper and colleagues reported three cases of posterior capsule rupture $(2.4 \%)$, one requiring vitrectomy $(1.2 \%)$, and one case of zonular dehiscence $(1.2 \%)$ during 41 cases of ISCS; none was bilateral and there were no cases of endophthalmitis. ${ }^{2}$ Pearce stated that during 129 cases of ISCS there were two holes in the posterior capsule $(0.8 \%)$ but no vitreous loss or endophthalmitis. ${ }^{17}$ Potamitis and colleagues reported no complications during 66 cases of ISCS. ${ }^{19}$ These figures compare favourably with the national rate of posterior capsular rupture and vitreous loss of $4.4 \%$ seen during unilateral cataract extraction surgery, ${ }^{14}$ and previously published rates of posterior capsular rupture and vitreous loss during phacoemulsification are $1.4-5.2 \%$ and $0.7-2.3 \%$ respectively, ${ }^{16}{ }^{20}$ and during ECCE are $0-8 \%{ }^{15} 2122$ and $0.09-3.3 \%,{ }^{15}{ }^{21-23}$ respectively.

CATASTROPHIC COMPLICATIONS

Suprachoroidal haemorrhage rates vary depending on the method used for cataract extraction, and the criteria used for diagnosis. We have been able to find eight reports of bilateral suprachoroidal haemorrhage associated with cataract surgery, $(0.004 \%) .^{24-28}$ In 15 eyes it occurred after intracapsular cataract extraction (ICCE), two of which were immediately sequential ICCE and one after ECCE. The outcome was the loss of both eyes in five cases, bilateral no perception of light (NPL) in one case, and 6/9 or better in two cases. In Payne's series of four, three had glaucoma, the interval between surgery varied from 4 days to 4 years, one patient's suprachoroidal haemorrhages occurred 12 hours postoperatively, and the ECCE achieved 6/9 acuity after 1 year of follow up. ${ }^{28}$ One large series estimated a rate of $0.013 \%$ following phacoemulsification and $0.12 \%$ following ECCE where cases converted to ICCE are excluded ( $p=0.0003)$. There were three cases occurring during phacoemulsification and all were limited, two of these were associated with posterior capsule rupture and took 8 and 12 weeks to resolve and achieved 0.5 and 0.8 , respectively. The other case took 6 weeks to resolve and achieved 0.3 acuity. ${ }^{29}$ The outcomes from another large series where phacoemulsification and ECCE were not divided were: $41 \%$ achieved 6/6-6/30, 6\% achieved $6 / 60-6 / 120,3 \%$ achieved $6 / 120$ to hand movements (HM), 29\% were perception of light (PL), and 15\% were NPL. ${ }^{30}$ A number of risk factors have been identified which increase the risk of occurrence, glaucoma 5.0 times (2.2-12.6, $\mathrm{p}<0.0001)$, axial length $>24 \mathrm{~mm} 4.7$ times $(2.0$ 
11.3, p <0.0001), intraoperative pulse rate more than 85 21.8 times $(6.4-73.9, \mathrm{p}<0.0001)$. Hypertension and diabetes mellitus were not significant risk factors. ${ }^{30}$ There were no cases of suprachoroidal haemorrhage associated with simultaneous bilateral phacoemulsification or ECCE. ${ }^{1-3} 17193132$ Patients with glaucoma and extremes of axial length are excluded from ISCS (Table 1).

EARLY POSTOPERATIVE COMPLICATIONS

Catastrophic complications

Endophthalmitis is widely regarded as a devastating complication of intraocular surgery. ${ }^{18}{ }^{30}{ }^{33-39}$ This has generated a huge amount of research on endophthalmitis. However, because of its relatively low incidence it is hard to clearly identify all the factors in its development. It has been established by DNA analysis techniques that the microorganisms causing endophthalmitis are commonly the patients' own commensal bacterial flora. ${ }^{30}$ The pooled data from anterior chamber contamination studies do not seem to relate to the endophthalmitis rate, ${ }^{37}{ }^{38}$ despite culturing an organism from $20-29 \%$ of anterior chambers there were no clinical cases of endophthalmitis in 510 cases studied. ${ }^{36-42}$ Preoperative antibiotics were not used in any of these studies, which suggests that an otherwise healthy eye can handle a small inoculum of bacteria (all of these studies excluded patients with ocular surface diseases, who might be expected to have different bacterial profiles and be at higher risk of endophthalmitis). Similarly, although there is general agreement that prophylactic antibiotics can be effective in reducing, but not eliminating, the risk of endophthalmitis, the optimal dosage, frequency, timing, and type of antibiotic have not been determined. ${ }^{18}{ }^{21}$ There were two cases of unilateral endophthalmitis after immediately sequential ECCE $\left(0.16 \%\right.$ and $0.19 \%$ respectively).$^{13}$ Bolger reported that after 350 cases of simultaneous bilateral cataract extraction there were two cases of endophthalmitis in different patients, a rate of $0.29 \%$, consistent with the rate in his unilateral surgery and other surgeons' published data. Of the 2859 mixed immediately sequential ECCE and phacoemulsification cases, there were four cases of endophthalmitis, none bilateral, a rate of $0.14 \% .^{1-317193132}$ This compares well with the national endophthalmitis rate of $0.1 \%,{ }^{14}$ our endophthalmitis rate following unilateral cataract extraction (0.12\%), and figures published for endophthalmitis after uncomplicated ECCE (0.18\%), complicated ECCE (1.10\%), uncomplicated phacoemulsification $(0.18 \%)$, and complicated phacoemulsification $(2.42 \%){ }^{18}{ }^{43-49}$ There has been one report of bilateral endophthalmitis following cataract surgery separated by 1 year. ${ }^{47}$ The presentation and outcome of endophthalmitis is strongly linked to the class of organism isolated. The acute form, has a fulminant presentation 2-4 days postoperatively. It is most frequently caused by virulent organisms such as Staphylococcus aureus (8-20\%), streptococci (9-22\%), and Gram negative organisms (6-22\%), and has a poor visual prognosis $(6 / 12$ or better in $10-20 \%)$. The delayed form occurs 5-7 days postoperatively, and is usually due to organisms of low virulence, such as the coagulase negative staphylococci and Propionibacterium spp (55-100\%), it is less severe and tends to be associated with a better outcome $(6 / 12$ or better in $46-100 \%) .^{394748}$ The size of the inoculum and specific host factors may influence the course that an individual case follows. When considering ISCS, conditions which might increase the bacterial load of the lids or conjunctiva, or which might impair the eye's natural defences are exclusion criteria (Table 1). When performing ISCS povidone iodine and postoperative subconjunctival antibiotics are always used to reduce bacterial viability and patients with an increased risk of infection are excluded
(Table 1) to minimise the chance of endophthalmitis. ${ }^{48} 50$ Second eye surgery is delayed if there is vitreous exposure, and a lens design with a proved "track record" is used. Lenses with polypropylene haptics were found to have a higher endophthalmitis rate than one piece PMMA lenses, $0.19 \%$ and $0.04 \%$ respectively. ${ }^{18}$ Steps taken to minimise the risk of epidemic endophthalmitis are minimal use of intracameral drugs, using viscoelastics, balanced saline solution, lenses from different batches, and instruments already proved by previous surgery. Waiting 48 hours is probably not long enough to be sure that a virulent organism is not going to cause simultaneous bilateral endophthalmitis. ${ }^{51}$ In one study only $86 \%$ of cases of endophthalmitis had presented by 34 days. ${ }^{47}$

NON-CATASTROPHIC COMPLICATIONS

Iris prolapse was seen bilaterally after immediately sequential ECCE in one patient $(0.18 \%)$, whose visual acuity at the last follow up visit was $6 / 9 .^{3}$ Unilateral iris prolapse occurred in $0.6 \%{ }^{1}$ There are no reports following immediately sequential phacoemulsification. ${ }^{2} 1713$ This compares well with $0.98 \%$ of unilateral ECCE and $0.2 \%$ of unilateral phacoemulsifications. ${ }^{51}$ In these cases of single eye surgery the scleral tunnel had been enlarged for a 7 $\mathrm{mm}$ lens but not sutured, all occurred on the first postoperative day, two resolved spontaneously, and one required repositioning. There were no cases following scleral tunnel and $5.5 \mathrm{~mm}$ lens insertion. ${ }^{51}$

Hyphaema was seen in $0.8 \%$ of cases following immediately sequential $\mathrm{ECCE}^{1}$ and in $0-1.2 \%$ following immediately sequential phacoemulsification. ${ }^{217}$ Both eyes were affected in $0.3-1.5 \%$ and the final visual acuity was $6 / 12$ or better. ${ }^{13}$ The national rate for unilateral surgery was $1.3 \%$ on the first postoperative day and had resolved in all cases by 3 months. ${ }^{15}$

Transient intraocular pressure (IOP) elevation was seen in $3.0 \%$ after immediately sequential ECCE, two cases were bilateral $(0.6 \%)$ and all achieved $6 / 12$ acuity or better. ${ }^{1}$ Transient IOP elevation occurred in $3.7 \%$ after immediately sequential phacoemulsification, but resolved by the second postoperative day. ${ }^{2}$ The national rate in 1993 for uniocular surgery was $5.3 \%$ on the first postoperative day and $2.3 \%$ by 3 months. ${ }^{15}$ Removing the viscoelastic from the anterior chamber at the end of surgery and the wide variety of agents for controlling intraocular pressure will help to reduce the frequency of this complication. We exclude patients from ISCS who are susceptible to increased postoperative anterior chamber inflammation with subsequent IOP rise, and glaucoma patients who may not tolerate a transient elevation in IOP.

Retinal detachment/tear was seen in one eye $(0.2 \%)$ after immediately sequential ECCE and achieved a final acuity of $6 / 12$. A second retinal detachment occurred as a complication of endophthalmitis and achieved a final visual acuity of counting fingers ${ }^{3}$; no other retinal detachments were reported after ISCS. ${ }^{1-3} 17$ 19-31 32 The national rate in 1999 was $0.1 \%$ by 3 months ${ }^{14}$ and in other large series it ranged from $0.7-1.0 \% .{ }^{16}{ }^{52}$ When retinal detachments occur later than this it is hard to isolate other aetiological factors, in particular the effect of Nd:YAG laser capsulotomy. Risk factors for the development of retinal detachment/tears after cataract surgery have been identified as intraoperative vitreous loss, high myopia, and previous ocular trauma, all of which are exclusion criteria for ISCS (Tables 1 and 2). With the advent of pars plana vitrectomy, $86-91 \%$ of retinal detachments can be reattached with one operation, if the macula is attached at the time of surgery the visual prognosis is good, with $83 \%$ of cases retaining or improving their acuity postoperatively. ${ }^{53}$

Refractive surprises were not encountered with the modern SBCS reports. Diaper and colleagues reported 
that the difference between best sphere after ISCS between each eye was $0.28 \mathrm{D}$ (SD 1.07D). ${ }^{2}$ Pearce achieved $72 \%$ within $0.5 \mathrm{D}$ of the preoperative astigmatism. ${ }^{17}$ When it comes to the astigmatic effects of scleral and corneal incisions for phacoemulsification, proponents will argue in favour of their technique. What all agree on is that the induced astigmatism changes with time. If there is concern over the refractive outcome, waiting 1 or 2 weeks is probably not sufficient time for the wound to stabilise. The refraction at 1 or 2 weeks postoperatively is unlikely to remain unaltered, because changes in astigmatism may continue for years postoperatively. ${ }^{54}$ If there is an unpredicted astigmatic outcome from the first eye, the adjustments made may or may not prevent it happening in the second eye. Fortunately, even when the astigmatic outcome is suboptimal, results show that with spectacle correction most patients still achieve good visual acuity. Following ISCS, $73 \%$ achieved $6 / 12$ or better uncorrected, $99 \%$ achieved $6 / 7.5$ best corrected visual acuity, ${ }^{17}$ which compares favourably with the national rate of $86 \%$ achieving 6/12 best corrected visual acuity. ${ }^{14}$ In extreme cases of postoperative refractive error, "piggy back IOL" may be implanted to correct it. The astigmatic changes induced by our incision were assessed after unilateral surgery, before commencing ISCS. Axial length and lens abnormalities, which may invalidate the biometry formulae used, are exclusion criteria for ISCS (Table 1).

\section{LATE POSTOPERATIVE COMPLICATIONS}

\section{Catastrophic complications}

Fungal endophthalmitis is rare and usually has a delayed presentation. It comprises $0-16.7 \%$ of cases in the published series on endophthalmitis. ${ }^{39} 49$ We have been able to find reports of 33 cases of fungal endophthalmitis following ECCE or phacoemulsification from North America and Europe published during the 1990s. ${ }^{34} 454755-68$ There were no cases from the UK published during the 1990s. The median onset was at 21 days (range 3-77 days), and the visual outcome varied, five were $6 / 7.5$ or better, three were $6 / 30$, four were $6 / 60$, one was HM, one was NPL, and five were enucleated or eviscerated. We have found only one report of simultaneous bilateral fungal endophthalmitis presenting after sequential phacoemulsification through a scleral tunnel, the surgeries were 3 weeks apart. The visual outcome was $6 / 120$ in one eye with an epiretinal membrane and $6 / 7.5$ in the other eye. ${ }^{67}$ Epidemics of fungal endophthalmitis can be caused by contamination of batches of solutions and ventilation systems. ${ }^{659-72}$ One such report describes 14 cases of Candida parapsilosis occurring over a 49 day period. The visual outcome was $6 / 12$ or better in $36 \%, 6 / 60$ or better in $72 \%$, counting fingers in $14 \%$, hand movements in $7 \%$, and no perception of light in $7 \% .{ }^{70}$ In another epidemic eight of 13 eyes infected by Paecilomyces subsequently required removal. ${ }^{69}$ To minimise the risk of epidemic endophthalmitis we use solutions and lenses from different batches when possible.

Epithelial ingrowth is a rare but potentially catastrophic complication. Although there are some large retrospective series, the risk of epithelial ingrowth is hard to estimate. In a review of 207 histological specimens collected over 50 years 123 followed cataract surgery; of these 21 followed ECCE and four phacoemulsification. ${ }^{73}$ The nature of the specimens analysed indicates the poor prognosis for the affected eye, enucleation specimens in 41 out of 120 , and corneal button 32 out of $120 .{ }^{74}$ The median interval between surgery and symptoms was 9 months (but the range was 1 week to 38 years), ${ }^{73}$ a shorter interval could not be considered an adequate guard against the very remote possibility of simultaneous bilateral epithelial ingrowth.
NON-CATASTROPHIC COMPLICATIONS

Cystoid macular oedema following immediately sequential ECCE occurred in 12 cases (1.9\%), none was bilateral. ${ }^{1}$ There were no other reports of cystoid macular oedema after ISCS. ${ }^{2}{ }^{17} 31$ The rate of angiographic oedema 60 days after phacoemulsification has been reported as $19 \%^{75}$; however, only $1.1 \%$ of cases tend to be clinically apparent, and the drop in VA is variable. ${ }^{52}$ The outcome of treatment is also variable and can depend on how aggressively it is treated. Cases that have not responded to topical non-steroidal anti-inflammatory drugs, topical steroids, or oral acetazolamide, may yet respond to high dose intravenous methylprednisolone. ${ }^{76} 77$ In order to reduce the risk of cystoid macular oedema diclofenac $0.1 \%$ eye drops are used to stabilise the blood-aqueous barrier and patients with diabetes mellitus and uveitis, who are more susceptible to blood-aqueous barrier breakdown, are excluded from ISCS. ${ }^{76}$ If during the course of the first operation there is vitreous exposure, surgery for the second eye is deferred. The fear of bilateral cystoid macular oedema is probably the most valid reason to delay surgery between eyes, but if it could not be prevented it in the first eye it may not be possible to prevent it in the second eye.

Corneal decompensation and subsequent pseudophakic bullous keratopathy has been estimated to occur following $0.3 \%$ of cataract extractions, and is related to endothelial cell loss. ${ }^{52}$ Transient epithelial oedema occurred after $0-2.4 \%$ of ISCS, but cleared in 2 days. $^{2}$ A case of bilateral endothelial failure over 6 months after ISCS resulted in $3 / 60$ vision in one eye and hand movements in the other. Bilateral penetrating keratoplasty was performed, unfortunately the graft failed in one eye, the subsequent vision was $1 / 60$, the successful graft achieved $6 / 36$. No mention of ocular comorbidity was made. ${ }^{78}$ Improved phacoemulsification machines and techniques allow cataracts to be removed with less and less energy. In addition, modern viscoelastics dampen the acoustic shock waves generated in proportion to their hyaluronic acid content. ${ }^{79}$ Despite this, no significant difference in mean cell loss after phacoemulsification has been found between $1 \%$ sodium hyaluronate (Healon), $1.4 \%$ sodium hyaluronate (Healon GV), $4 \%$ sodium chondroitin sulphate-3\% sodium hyaluronate (Viscoat) and 2\% hydroxypropyl methylcellulose (Hymecel). ${ }^{80}$ Although we exclude patients with endothelial dystrophies or significant guttata, even corneas that appear normal preoperatively may fail postoperatively. ${ }^{78}$ The time over which this occurs is variable; thus, a short interval between cataract surgeries may not eliminate the risk. In addition, endothelial failure in one eye may lead the patient to request surgery for the other eye. In the future, the routine use of Healon 5, preoperative specular microscopy, and pachymetry may be used to further reduce the risk of bilateral endothelial failure.

\section{Are the risks acceptable?}

Not all simultaneous or immediately sequential surgery attracts such controversy. Immediately sequential blepharoplasty with the risk of bilateral retrobulbar haemorrhage is routinely carried out. ${ }^{81}$ Bilateral extraocular muscle surgery for the correction of strabismus with the risk of bilateral retinal detachment or endophthalmitis following globe perforation is routinely carried out in children. ${ }^{82} 83$ Immediately sequential laser in situ keratomilieusis (LASIK) with the risk of bilateral microkeratome complications and epithelial ingrowth ${ }^{84}$ is also performed. These immediately sequential bilateral procedures are considered acceptable, not because the risks have been eliminated but rather because the benefits are believed to 
Table 3 The estimated risk of simultaneous bilateral complications in otherwise uncomplicated surgery

\begin{tabular}{|c|c|c|c|c|c|c|c|}
\hline \multirow[b]{2}{*}{ Risk estimate } & \multicolumn{4}{|c|}{ Eyes are independent } & \multicolumn{3}{|c|}{ Eyes are not independent } \\
\hline & First eye & Second eye & Either eye & Both eyes & Second eye & Either eye & Both eyes \\
\hline \multicolumn{8}{|l|}{ (A) Expulsive haemorrhage } \\
\hline Upper limit ${ }^{29}$ & 1 in 833 & 1 in 833 & 1 in 417 & 1 in 694000 & 1 in $6.5^{\star}$ & 1 in 6.4 & 1 in 5400 \\
\hline Lower limit ${ }^{28}$ & 1 in 7692 & 1 in 7692 & 1 in 3846 & 1 in 60000000 & 1 in $6.5^{\star}$ & 1 in 6.5 & 1 in 50000 \\
\hline \multicolumn{8}{|l|}{ (B) Bacterial endophthalmitis } \\
\hline Upper limit ${ }^{47}$ & 1 in 555 & 1 in 555 & 1 in 278 & 1 in 308000 & 1 in $84 \dagger$ & 1 in 73 & 1 in 46600 \\
\hline Lower limit ${ }^{39}$ & 1 in 2141 & 1 in 2141 & 1 in 1072 & 1 in 4580000 & 1 in $84 \dagger$ & 1 in 81 & 1 in 180000 \\
\hline \multicolumn{8}{|l|}{ (C) Fungal endophthalmitis } \\
\hline $1990 \mathrm{~s}$ & 1 in $4.62 \times 10^{6} \ddagger$ & 1 in $4.62 \times 10^{6}$ & 1 in $2.31 \times 10^{6}$ & 1 in $2.13 \times 10^{13}$ & 1 in 325 & 1 in 32 & 1 in $1.20 \times 10^{8}$ \\
\hline
\end{tabular}

${ }^{\star}$ Based on ICCE rate. ${ }^{28}$

+Somani et al..$^{47}$

$\ddagger$ Derived from 33 cases of published fungal endophalmitis following an estimated 120 million cataract extractions in the USA in the 1990 s. ${ }^{18} 4547555658-6365-68$

jWeissgold et al. ${ }^{67}$

outweigh the risks. Many intraoperative and postoperative complications have been reduced by the transition from ECCE to phacoemulsification. Developments continue to be described that aim to improve the outcome of phacoemulsification, and make it an even safer procedure, but there will never be a risk free surgical procedure. With every step of every operation there are choices that require balancing risks and benefits. Currently the benefits of ISCS are more clearly defined than the risks (Table 2). Estimates of risk vary from "Many things could go wrong during single-eye surgery, and bilateral surgery doubles the chances for error" 17 at one end, to "The risk of bilateral endophthalmitis is no greater than the risk of two sequential patients on an operating list developing endophthalmitis. If a generous endophthalmitis rate of $0.1 \%$ is assumed, an ophthalmologist would have to carry out one million cataract operations before two would become infected sequentially. Even the highest volume cataract surgeons would never get near this number in their operating lifetime" ${ }^{31}$ at the other. It seems likely that the risk will lie somewhere between these two extremes.

Say the risk of a given complication is one in $\mathrm{Y}$ cases or $1 / \mathrm{Y}$. The risk of a complication in either eye is $1 / \mathrm{Y}+1 / \mathrm{Y}=$ $2 / Y$. If the eyes are independent the risk of a complication in the second eye is the same as that in the first eye, $1 / \mathrm{Y} \times$ $1 / \mathrm{Y}=1 / \mathrm{Y}^{2}$. However, if the patient has an underlying propensity for a complication the risk for the second eye is not independent of the first eye and separating the surgeries is no guarantee that bilateral complications will not occur. ${ }^{28} 4767$

The concept is of conditional probability - that is, the likelihood of the event occurring a second time if it has occurred once already. Maloney estimates if the first eye has a complication then the second will also have the complication one in three times - that is, $1 / 3 \mathrm{Y}$ with LASIK or photorefractive keratectomy. ${ }^{84}$

We have attempted to make similar calculations for the catastrophic complications cited in Table 2. We have searched the literature for cases where both eyes have been affected by expulsive haemorrhage, epithelial ingrowth, and bacterial or fungal endophthalmitis following cataract extraction. ${ }^{29} 4767$ These cases have been used to estimate the risk of a patient suffering a catastrophic complication in the second eye if it has already occurred in the first eye (Table 3).

Payne and colleagues reported the 14 eyes with expulsive haemorrhage between 1978 and 1983. In this survey one patient experienced bilateral expulsive haemorrhage associated with cataract extraction and another had their first expulsive haemorrhage at another hospital. ${ }^{29}$ The risk to the second eye, after the first has been affected by expulsive haemorrhage, can therefore be estimated as two in 13 or one in 6.5 .
Somani and colleagues reported 85 eyes with culture proved bacterial endophthalmitis following ECCE or phacoemulsification between 1989 and 1996, two of these were from the same patient. ${ }^{47}$ The risk to the second eye, after the first has been affected by bacterial endophthalmitis, can therefore be estimated as one in 84 .

There were no large series of fungal endophthalmitis following cataract surgery. We have pooled the cases of fungal endophthalmitis following cataract extraction from North America and Europe published during the 1990s. We were able to find 33 cases of fungal endophthalmitis by combining cases from series on endophthalmitis and individual reports, and there was only one patient with both eyes affected. ${ }^{67}$ The risk to the second eye, after the first has been affected by fungal endophthalmitis, can be very approximately estimated as one in 32. This method would be expected to underestimate the risk to the first eye because not all the cases will be published. However, it will overestimate the risk to the second eye if no cases of bilateral fungal endophthalmitis have been missed.

We were unable to find any reports of bilateral epithelial ingrowth after modern cataract surgery.

Table 3 shows the estimated risks if the complications are considered as independent or not, for the first eye and then the second eye. This clearly demonstrates that the risk of both eyes being affected simultaneously is a small fraction of one eye being affected at a time.

A complication in the first eye may unnecessarily deter the patient from further surgery to the second eye, to the extent that the patient dies blind.$^{85}$ It is not simply a question of mathematics and Snellen acuity. A surgeon's attitude to the risk of bilateral complications after ISCS might depend on when, if ever, they arose. Good results from 9999 patients before the 10 000th suffers a bilateral catastrophic complication might leave a very different impression than if the first patient suffered a catastrophic bilateral complication.

\section{Conclusion}

The risks of ISCS are low if patients suspected of having an underlying predisposition to complications are excluded (Table 1). There are significant, but hard to quantify, benefits to the patient, hospital, and society with ISCS. We are not suggesting that ISCS is for everyone (surgeon and patient alike), but that the stigma attached to ISCS is removed until evidence is found to justify it.

GUY T SMITH CHRISTOPHER S C LIU

Sussex Eye Hospital, Eastern Road, Brighton BN2 5BF, UK

Correspondence to: $\mathrm{Mr}$ Christopher Liu CSCLiu@aol.com 
1 Beatty A, Aggarwal RK, David DB, et al. Simultaneous bilateral cataract extraction in the UK. Br F Ophthalmol 1995;79:1111-14.

2 Diaper CJM, Beirouty ZAY, Saba SN. Simultaneous bilateral phacoemulsification. Eur F Implant Ref Surg 1995;7:232-5.

3 Ramsay AL, Diaper CJM, Saba SN, et al. Bilateral simultaneous cataract surgery. F Cataract Refract Surg 1999;2254:753-62.

4 Cataract Management Guidelines Panel. Cataracts in adults: management of functional impairment: clinical practice guide number 4. Rockville, MD: US Dept of Health and Human Service, Agency for Health Care Policy and Research; February 1993. AHCPR publication 93-0542.

5 Donderi DC, Murphy SB. Predicting activity and satisfaction following cataract surgery. F Behav Med 1983;6:313-28.

6 Applegate WB, Miller ST, Elam JT, et al. Impact of cataract surgery with lens implantation on visual and physical function in elderly patients. $f A M A$ 1987;257:1064-6.

7 Javitt JC, Bremner HM, Curbow B, et al. Outcomes of cataract surgery. Improvement in visual acuity and subjective visual function after surgery in the first, second and both eyes. Arch Ophthalmol 1993;111:686-91.

8 Laidlaw A, Harrad R. Can second eye cataract be justified? Eye 1993;7:6906.

9 Steinberg EP, Tielsch JM, Schein OD, et al. The VF14: an index of functional Impairment in patients with cataract. Arch Ophthalmol 1994; 112:630-8.

10 Lundström M, Fregell G, Sjöblom. Vision related daily life problems in patients waiting for cataract extraction. Br f Ophthalmol 1994;78:608-11.

11 Mangione CM, Orav EJ, Lawrence MG, et al. Prediction of visual function after cataract surgery: a prospectively validated model. Arch Ophthalmol 1995:113:1305-11.

12 Crabtree HL, Hildreth AJ, O'Connell JE, et al. Measuring visual symptoms in British cataract patients: the cataract symptom scale. Br 7 Ophthalmol 1999;83:519-23.

13 Desai P, Reidy A, Minassian DC, et al. Gains from cataract surgery: visual function and quality of life. Br F Ophthalmol 1996;80:868-73.

14 Desai P, Reidy A, Minassian DC. Profile of patients presetning for catarct surgery in the UK: national data collection. Br f Ophthalmol 1999;83:893-6.

15 Desai P. The national cataract surgery survey: II clinical outcomes. Eye 1993;7:498-4.

16 Wegener M, Alsbirk PH, Højgaard-Olsen K. Outcome of 1000 consecutive clinic- and hospital-based cataract surgeries in a Danish county. $\mathcal{F}$ Cataract Refract Surg 1998;24:1152-60.

17 Masket S, ed. Cataract surgical problem: under what conditions do you perform/consider bilateral simultaneous cataract extraction with intraocular lens (IOL) implantation. What special precautions do you take/advise when considering bilateral surgery? F Cataract Refract Surg 1997; 23:1437-41.

18 Menikoff JA, Speaker MG, Marmor M, et al. A case-control study of risk factors for post operative endophthalmitis. Ophthalmology 1991;98: 1761-8.

19 Potamitis T, Beatty S, Pereira AM, et al. Phacoemulsification versus endocapsular cataract extraction in a unique cohort of patients. Eye 1996; 10:551-4.

$20 \mathrm{Ng}$ DT, Rowe NA, Francis IC, et al. Intraoperative complications of 1000 phacoemulsification procedures: a prospective study. $\mathcal{F}$ Cataract Refract Surg 1998;24:1390-5.

21 Stark WJ, Maumanee A, Datiles M. Intraocular complications and results. Trans Am Ophthalmol Soc 1983;81:280-309.

22 O'Donnell Jr FE, Santos BA. Prospective study of posterior capsule-zonular disruption. I Cataract Refract Surg 1990;16:329-32.

23 Silvestri G, Shepard WF, Johnston PB. Pseudophakic retinal detachment and post operative visual acuity. Int Ophthalmol 1989;15:9-12.

24 Danielson RW. In discussion, Henderson JW. Expulsive subchoroidal haemorrhage associated with cataract extraction. Trans Am Ophthalmol Soc 1959; 57:195-209.

25 Castroviejo R. In discussion, Henderson JW. Expulsive subchoroidal haemorrhage associated with cataract extraction. Trans Am Ophthalmol Soc 1959; 57:195-209.

26 Berens C. in discussion, Henderson JW. Expulsive subchoroidal haemorrhage associated with cataract extraction. Trans Am Ophthalmol Soc 1959;57:195-209.

27 Francois PM, Wannebroucg L, Guilber-Legand M. Les Hemorragies expulsives: a propos de 6 ca. Bull Soc Ophtalmol Fr 1966:59-585.

28 Payne JW, Kameen AJ, Jensen AD, et al. Expulsive haemorrhage its incidence: in cataract surgery and a report on 4 bilateral cases. Trans Am Ophthalmol Soc 1985;83:181-204.

29 Erikson A, Koranyi G, Seregard S, et al. Risk of suprachoroidal hemorrhage with phacoemulsification. F Cataract Refract Surg 1998;24:793-800.

30 Speaker MJ, Guerriero.PN, Met JA, et al. A case-control study of risk factors for intraoperative suprachoroidal haemorrhage. Ophthalmology 1991;98: 202-10.

31 Bolger J. Letter. F Cataract Refract Surg 1998;24:430-1.

32 Arshinoff S. Letter. $\mathcal{F}$ Cataract Refract Surg 1998;24:1015-16.

33 Speaker MJ, Menikoff JA. Prophylaxis of endophthalmitis with topical povidone-iodine. Ophthalmology 1991;98:1769-75.

34 Joosse MV, Van Tilburg CJG, Mertens DAE, et al. Endophthalmitis: incidence, therapy and visual outcome in the period 1983-1992 in the Rotterdam Eye Hospital. Doc Ophthalmol 1992;83:115-23.

35 Heaven CJ, Mann PJ, Boase DL. Endophthalmitis following extracapsular cataract surgery: a review of 32 cases. Br f Ophthalmol 1992;76:419-23.

36 Egger SF, Huber-Spitzy V, Scholda C, et al. Bacterial contamination during extracapsular cataract extraction. Ophthalmologica 1994;208:77-81.

37 Mistleberger A, Ruckhofer J, Raithel E, et al. Anterior chamber contamination during cataract surgery with intraocular lens implantation. $\mathcal{f}$ Cataract Refract Surg 1997;23:1064-9.

38 Assia EI, Jubran RZ, Solberg Y, et al. The role of intraocular lenses in anterior chamber contamination during cataract surgery. Graefes Arch Clin Exp Ophthalmol 1998;236:721-4.

39 Bohigan GM. A study of the incidence of culture positive endophthalmitis after cataract surgery in an ambulatory care centre. Ophthalmic Surg Lasers 1999;30:295-8.
40 Egger SF, Huber-Spitzy V, Skorpik C, et al. Different techniques of extracapsualr cataract extraction, bacterial contamination during surgery. Graefes Arch Clin Exp Ophthalmol 1994:232:308-11.

41 Manners TD, Chitkara DK, Marsh PJ, et al. Anterior chamber aspirate culture in small incision cataract surgery. Br f Ophthalmol 1995;79:878-80.

42 Beigi B, Westlake W, Mangelschots E, et al. Peroperative microbial contamination of anterior chamber aspirates durin extracapsular cataract extraction and phacoemulsification. Br f Ophthalmol 1997;81:953-5.

43 Javitt JC, Vitale S, Canner JK, et al. National outcomes of cataract extraction. Arch Ophthalmol 1991;109:1085-9.

44 Kattan HM, Flynn HW, Pflugfelder SC, et al. Nosocomial endophthalmitis survey: current incidence of infection after intraocular surgery. Ophthalmology 1991;98:227-38.

45 Fox GM, Joondelp BC, Flynn HW, et al. Delayed onset pseudophakic endophthalmitis. Am f Ophthalmol 1991;111:163-73.

46 Hughes DS, Hill RJ. Infectious endophthalmitis after cataract surgery. $\mathrm{Br} \mathcal{F}$ Ophthalmol 1994;78:227-32.

47 Somani S, Grinbaum A, Slomovic AR. Post operative endophthalmitis: incidence, predisposing surgery, clinical course and outcome. Can $\mathcal{f}$ Ophthalmol 1997;32:303-10.

48 Lehmann OJ, Roberts CJ, Ikram K, et al. Association between non administration of subconjunctival cefuroxime and postoperative endophthalmitis. f Cataract Refract Surg 1997;23:889-93.

49 Kunimoto DY, Das T, Sharma S, et al. Microbiological spectrum and susceptibility of isolates: Part 1. Postoperative endophthalmitis. Am f Ophthalmol 1999;128:240-2.

50 Isenberg, SJ, Apt L, Yoshimuri R, et al. Chemical preparation of the eye in ophthalmic surgery. IV. Comparison of povidone-iodine on the conjunctiva with prophylactic antibiotic. Arch Ophthalmol 1985;103:1340-2.

51 Booth A, Coombes A, Rostron C. Bilateral cataract extraction can be safely done within 48 hours. BMF 1999;319:579.

52 Francis PJ, Morris RJ. Post-operative iris prolapse following phacoemulsification and extracapsular cataract surgery. Eye 1997;11:87-90.

53 Powe NR, Schein OD, Gieser SC, et al. Synthesis of the literature on visual acuity and complications following cataract extraction with intraocular lens implantation. Arch Ophthalmol 1994;112:889, or 239-52.

54 Campo RV, Sipperley JO, Sneed SR, et al. Pars plane vitrectomy without scleral buckle for pseudophakic retinal detachments. Ophthalmology 1999;106:1810-16.

55 Olsen RJ, Crandall AS. Prospective randomised comparison of phacoemulsification cataract surgery with a $3.2-\mathrm{mm}$ vs a $5.5-\mathrm{mm}$ sutureless incision. Am $\mathcal{F}$ Ophthalmol 1998;125:612-20.

56 Rao NA, Nerenberg AV, Forster DJ. Torulopsis candida (Candida famata) endophthalmitis simulating Propionobacterium acnes syndrome. Arch Ophthalmol 1991;109:1718-21.

57 Bouchard CS, Chacko B, Cupples HP, et al. Surgical treatment for a case of postoperative Pseudallescheria boydii endophthalmitis. Ophthalmic Surg 1991;22:98-101.

58 Verbraeken HEG. Intracapsular and extracapsular pseudophakic endophthalmitis: a comparison. Doc Ophthalmol 1993;84:387-93.

59 Kauffman CA, Bradley SF, Vine AK. Candida endophthalmitis associated with intraocular lens implantation: efficacy of fluconazole therapy. Mycoses 1993;36:13-17.

60 Borne MJ, Elliot JH, O’Day DM, Ocular fluconazole treatment of Candida parapsilosis endophthalmitis after failed intravitreal amphotericin B [letter]. Arch Ophthalmol 1993;111:1326-7.

61 Rosenfelt SI, Jost BF, Litinsky SM, et al. Persistent Torulopsis magoliae endophthalmitis following cataract extraction. Ophthalmic Surg 1994;25: 154-6.

62 Lee BL, Grossniklaus HE, Capone A Jr, et al. Ovadendron sulphureoochraceum endophthalmitis after cataract surgery. Am F Ophthalmol 1995; 119:307-12.

63 Fekrat S, Haller JA, Green WR, et al. Pseudophakic Candida parapsilosis endophthalmitis with a consecutive keratitis. Cornea 1995;14:212-16.

64 Oxford KW, Abbott RL, Fung WE, et al. Aspergillus endophthalmitis after sutrueless cataract surgery. Am f Ophthalmol 1995;120:534-5.

65 Bartz-Schmidt KU, Tintelnot K, Steffen M, et al. Chronic basidiomycetous endophthalmitis after extracapsular cataract extraction and intraocular lens implantation. Graefes Arch Clin Exp Ophthalmol 1996;234:591-3.

66 Fridkin SK, Kremer FB, Bland LA, et al. Acremonium kiliense endophthalmitis that occurred after cataract extraction in an ambulatory surgical centre and was traced to an environmental reservoir. Clin Infect Dis 1996;22:222-7.

67 Weissgold DJ, Maguire AM, Brucker AJ. Management of postoperative Acremonium endophthalmitis. Ophthalmology 1996;103:749-56.

68 Wong VKW, Tasman W, Eagle RC, et al. Bilateral candida parapsilosis endophthalmitis. Arch Ophthalmol 1997;115:670-2.

69 Weissgold DJ, Orlin SE, Sulewski ME, et al. Delayed onset fungal keratitis after endophthalmitis. Ophthalmology 1998;105:258-62.

70 Samples JR, Binder PS. Contamination of irrigating solution used for cataract surgery. Ophthalmic Surg 1984;15:6.

71 Stern WH, Tamura E, Jacobs RA, et al. Epidemic post sugical candida parapsilosis endophthalmitis. Ophthalmology 1985;92:1701-9.

72 O'Day DM, Head WS, Robinson RD. An outbreak of Candida parapsilosis endophthalmitis: analysis of strains by enzyme profile and antifungal susceptibility. Br 7 Ophthalmol 1987;71:126-9.

73 McCray E, Rampell N, Solomon SL, et al. Outbreak of Candida parapsilosis endophthalmitis after cataract extraction and intraocular lens implantation. f Clin Microbiol 1986;24:625-8.

74 Küchle M, Green WR. Epithelial ingrowth: a study of 207 proven cases. Ger f Ophthalmol 1996;5:211-23.

75 Weiner MJ, Trentacoste J, Pon DM, et al. Epithelial downgrowth: a 30-year clinicopathological review. Br f Ophthalmol 1989;73:6-11.

76 Ursell PG, Spalton DJ, Whitcup SM, et al. Cystoid macular edema after phacoemulsification: relationship to blood-aqueous barrier damage and visual acuity. F Cataract Refract Surg 1999;25:1492-7.

77 Rossetti L, Chaudhuri J, Dickersin K. Medical prophylaxis and treatment of cystoid macular edema after cataract surgery. Ophthalmology 1998;105: 397-405.

78 Abe T, Hayasaka S, Nagaki Y, et al. Pseudophakic cystoid macular edema treated with high dose intravenous methylprednisolone. $\mathcal{F}$ Cataract Refract Surg 1999;25:1286-8. 
79 Tyagi AK, McDonnell PJ. Visual impairment due to bilateral corneal endothelial failure following simultaneous bilateral cataract surgery. $\mathrm{Br} \mathcal{F}$ endothelial failure following

80 Frohn A, Dick HB, Fritzen CP, et al. Ultrasonic transmission in viscoelastic substances. $\mathcal{F}$ Cataract Refract Surg 2000;26:282-6.

81 Ravalico G, Tognetto D, Palomba MA, et al. Corneal endothelial function after extracapsular cataract extraction and phacoemulsification. $\mathcal{F}$ Cataract Refract Surg 1997;23:433-9.

82 Anderson RL, Edwards JJ. Bilateral visual loss after blepharoplasty. Ann Plast Surg 1980;5:288-92.
83 Apple DJ, Jones GR, Reidy JJ, et al. Ocular perforation and phthisis bulbi secondary to strabismus surgery. $\mathcal{F}$ Pediatr Ophthalmol Strabismus 1985;22: $18-187$.

84 Simon JW, Liniger LL, Scheraga JL. Recognised scleral perforation during eye muscle surgery: incidence and sequelae. F Pediatr Ophthalmol Strabismus 1992;29:273-5.

85 Gimbel HV, van Westenbrugge JA, Anderson Penno EE, et al. Simultaneous bilateral laser in situ keratomileusis. Safety and efficacy. Ophthalmology 1999;106:1461-8.

86 Steinmetz B. Letter. $\mathcal{F}$ Cataract Refract Surg 1998;24:430-1 